\title{
BMC
}

Neuroscience

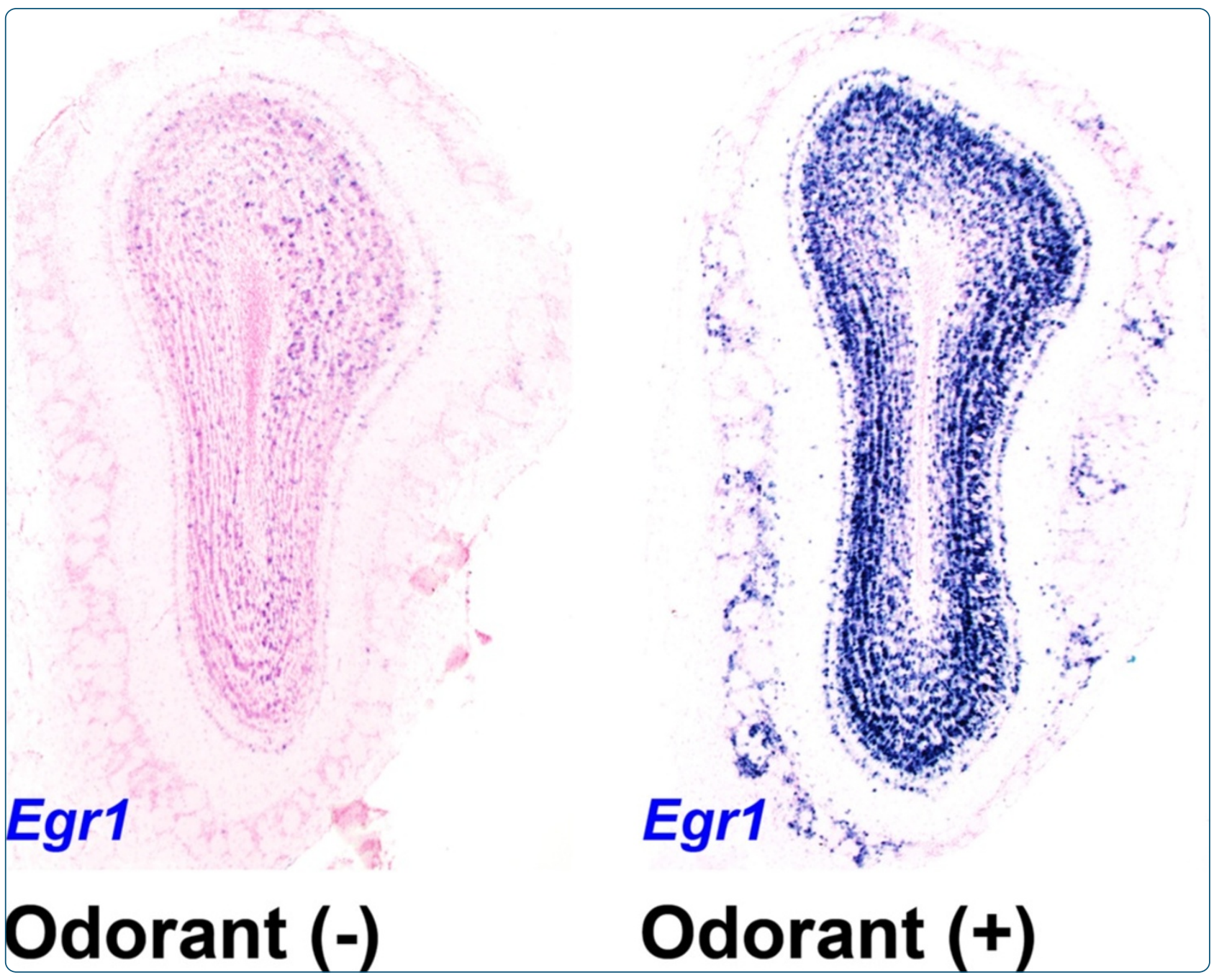

\section{Visualization of odor-induced neuronal activity by immediate early gene expression}

Bepari et al.

() Biomed Central 


\title{
Visualization of odor-induced neuronal activity by immediate early gene expression
}

\author{
Asim K Bepari ${ }^{1,2}$, Keisuke Watanabe ${ }^{2}$, Masahiro Yamaguchi ${ }^{3}$, Nobuaki Tamamaki ${ }^{1}$ and Hirohide Takebayashi ${ }^{2,4^{*}}$
}

\begin{abstract}
Background: Sensitive detection of sensory-evoked neuronal activation is a key to mechanistic understanding of brain functions. Since immediate early genes (IEGs) are readily induced in the brain by environmental changes, tracing IEG expression provides a convenient tool to identify brain activity. In this study we used in situ hybridization to detect odor-evoked induction of ten IEGs in the mouse olfactory system. We then analyzed IEG induction in the cyclic nucleotide-gated channel subunit A2 (Cnga2)-null mice to visualize residual neuronal activity following odorant exposure since CNGA2 is a key component of the olfactory signal transduction pathway in the main olfactory system.

Results: We observed rapid induction of as many as ten IEGs in the mouse olfactory bulb (OB) after olfactory stimulation by a non-biological odorant amyl acetate. A robust increase in expression of several IEGs like c-fos and Egrl was evident in the glomerular layer, the mitral/tufted cell layer and the granule cell layer. Additionally, the neuronal IEG Npas4 showed steep induction from a very low basal expression level predominantly in the granule cell layer. In Cnga2-null mice, which are usually anosmic and sexually unresponsive, glomerular activation was insignificant in response to either ambient odorants or female stimuli. However, a subtle induction of $c$-fos took place in the $\mathrm{OB}$ of a few Cnga2-mutants which exhibited sexual arousal. Interestingly, very strong glomerular activation was observed in the $\mathrm{OB}$ of Cnga2-null male mice after stimulation with either the neutral odor amyl acetate or the predator odor 2, 3, 5-trimethyl-3-thiazoline (TMT).

Conclusions: This study shows for the first time that in vivo olfactory stimulation can robustly induce the neuronal IEG Npas4 in the mouse OB and confirms the odor-evoked induction of a number of IEGs. As shown in previous studies, our results indicate that a CNGA2-independent signaling pathway(s) may activate the olfactory circuit in Cnga2-null mice and that neuronal activation which correlates to behavioral difference in individual mice is detectable by in situ hybridization of IEGs. Thus, the in situ hybridization probe set we established for IEG tracing can be very useful to visualize neuronal activity at the cellular level.
\end{abstract}

Keywords: Olfaction, Odorant map, Olfactory bulb, Cnga2, Immediate early gene (IEG)

\section{Background}

Chemosensory cues from the environment are detected by the peripheral nervous system which then transmits sensory information to the central nervous system and activates discrete neuronal ensembles. Studies on patterns of neuronal activation provide useful insights into roles of different neuronal population and brain regions

\footnotetext{
* Correspondence: takebaya@med.niigata-u.ac.jp

${ }^{2}$ Division of Neurobiology and Anatomy, Graduate School of Medical and Dental Sciences, Niigata University, Niigata, Japan

${ }^{4}$ PRESTO, Japan Science and Technology Agency (JST), Kawaguchi, Saitama, Japan

Full list of author information is available at the end of the article
}

in regulating distinct animal behaviors. IEG expression is induced rapidly when neurons are activated by membrane depolarization, seizure or some sensory signals [1] and the expression pattern of IEGs is a convenient tool for visualization of neuronal activities [2-4]. Neuronal IEGs comprise of several categories including transcription factors (c-fos, Fosb, c-jun, Junb, Egr1, Egr2, Egr3, Npas4, Nr4a1, Nr4a2, etc.) and postsynaptic proteins (Arc, Homer1a, etc.). Previous studies which used longterm potentiation (LTP) or long-term enhancement paradigm indicated that different IEGs have different thresholds for transcriptional induction; $c$-fos, for instance, has a high threshold compared to that of Egr1

\section{Biomed Central}


[5,6]. Guzowski et al., (2001) found a higher responsiveness of Arc than that of $c$-fos and Egr1 in the rat hippocampus after spatial learning [7].

Olfactory sensory neurons (OSNs) in the main olfactory epithelium (MOE) can detect a vast array of odorous molecules by the olfactory receptors (ORs) [8]. OSNs make synapses directly to second-order neurons in the central nervous system. Each OSN projects to a single glomerulus and the OSNs which express a particular OR usually converge to a single glomerulus both in the medial and lateral halves of the $\mathrm{OB}$ and thus $\mathrm{OB}$ glomeruli form a topographical map of ORs $[9,10]$. Consequently, afferent inputs through OSNs trigger activity in the $\mathrm{OB}$ which is often traced by specific induction of IEGs. However, it should be noted that in addition to peripheral stimulation, centrifugal inputs can significantly influence the pattern of activity in the OB, particularly in the granule cell layer [11-14].

Interaction of odorants with ORs in vertebrate OSNs activates the olfaction-specific $G$ protein $\left(G_{\text {olf }}\right)$ which in turn stimulates other components of the signaling cascades including the adenylyl cyclase type III (ACIII) and the olfactory cyclic nucleotide-gated channel (CNGC) [15]. Previous knockout mice studies have confirmed that the CAMP signaling pathway plays the key role for detection of odorants [16,17]. Belluscio et al. (1998) reported that most $\mathrm{G}_{\mathrm{olf}}$-deficient mice showed neonatal mortality [17]. In addition, electro-olfactogram (EOG) recordings, which measure electrical activity detected by an electrode placed on the olfactory epithelium, indicated severe reduction in odor-evoked response in $\mathrm{G}_{\text {olf }^{-}}$ deficient mice [17]. The odorant-induced EOG response was found to be completely ablated and the odorantdependent avoidance learning was impaired in ACIII mutant mice [18]. The mice which have mutation in the cyclic nucleotide-gated channel subunit A2 (Cnga2) gene also show general anosmia [19]. In 1 day-old Cnga2mutants there was no detectable EOG response even when the olfactory epithelium was exposed to complex olfactory stimuli such as mouse urine (conspecific odor cues) or coyote urine (predator odor cues) [19]. Behavioral studies in adult Cnga2-null male mice showed that they fail to mate or fight and it is suggested that the MOE has an essential role in regulating these social behaviors [20]. Although the mutant male mice failed to show preference for female urine [20], it remains unclear whether the female urine odor activated the OB glomeruli or not. Intriguingly, Lin et al. (2004) showed that several odorants, including putative pheromones, were behaviorally detected by the Cnga2-null mice and electrophysiological and immunohistochemical studies revealed that those odors indeed produced responses in the MOE, $\mathrm{OB}$ and piriform cortex $(\mathrm{PC})$ in the mutants [21].
For mapping neuronal activity using IEGs two important criteria should be the low basal expression and the high induction of the IEG being used. It is also advantageous to analyze several IEGs since the induction thresholds of IEGs vary depending on the IEG, the stimulus and the tissue. In this present study we used ISH to analyze expression patterns of ten IEGs in the mouse brain using different odor stimuli and compared inducibility and sensitivity of these IEGs for detection of sensory-evoked neuronal activities. We then asked how disruption of the cAMP signaling cascade in the olfactory pathway affects neuronal activation using Cnga2null male mice which show general anosmia and sexual deficits. We exposed the mutants to different odorants including a predator odor and female odors to observe behavioral responses and the pattern of brain activities mediated by any CNGA2-independent olfactory signaling pathway(s) using ISH of IEGs.

\section{Results}

\section{Odor-evoked rapid induction of ten activity-dependent} genes in the mouse $\mathrm{OB}$

To visualize neuronal activities in response to environmental changes we used ISH of activity-dependent genes in the mouse brain following presentation of odor stimuli. To minimize the level of ambient odorants, test animals were kept under overhead air flow for $2 \mathrm{~h}$ before the odorant exposure. The mice which were sacrificed immediately after the 2-h air exposure were treated as controls, the 'Odorant (-)' group. IEG expression levels were found to be very low in control mice (Figure 1A1-J1, A1'-J1', Figure 2). For olfactory stimulation we first used amyl acetate since it is a standard nonbiological odorant which produces strong and repeatable responses [22,23]. As many as ten IEGs were induced when the mice were exposed to amyl acetate for $25 \mathrm{~min}$ (5-min exposures with 5-min intervals) and sacrificed after $30 \mathrm{~min}$ from the odor onset (AA $25 \mathrm{~min}$, air $5 \mathrm{~min}$ ) (Figure 1A2-J2, A2'-J2', Figure 2). Expression levels of most of these IEGs decreased substantially within $60 \mathrm{~min}$ of the odor onset (AA $25 \mathrm{~min}$, air $35 \mathrm{~min}$ ) (Figure 1A3-J3, Figure 2), indicating that the odor-evoked IEG induction was transient. Nevertheless, odorant-induced higher expression levels of Egr3 (Figure 1E1-E3), Fosb (Figure 1F1-F3) and Nor1 (Figure 1H1-H3) seemed to be sustained at least for $60 \mathrm{~min}$ from the initial odor presentation.

The main projection neurons in the mouse $\mathrm{OB}$ are the mitral/tufted cells and there are several types of interneurons such as granule cells and periglomerular cells. We could visualize activation of spatially segregated glomeruli by the strong $c$-fos expression in periglomerular cells (arrow, Figure 1A2, A2') even though the ISH signals spanned the entire glomerular layer. The $c$-fos mRNA signals were abundant in the mitral/tufted cell 

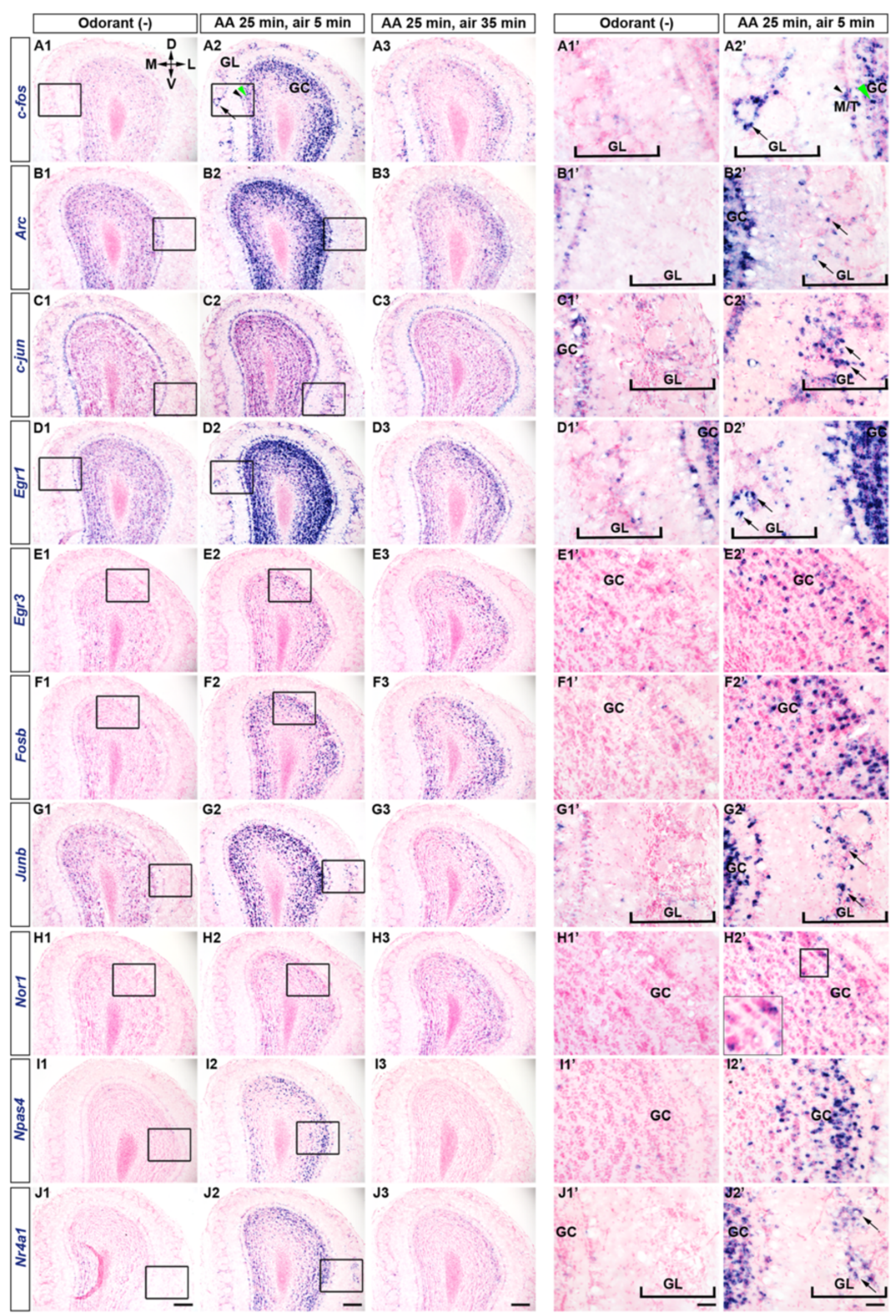

Figure 1 (See legend on next page.) 
(See figure on previous page.)

Figure 1 Odorant (amyl acetate) exposure induced the expression of IEGs in the mouse OB. Mice were exposed to overhead airflow for $2 \mathrm{~h}$ and then to the test odorant (amyl acetate) for 25 min (5-min exposures with 5-min intervals). The ISH of coronal sections of OB indicated low expression levels of ten IEGs in mice immediately after the 2-h air exposure, (Odorant (-), A1-J1, A 1'-J1'). All these ten IEGs were induced in the mouse $O B$ after 30 min of odor onset (AA 25 min, air 5 min, A2-J2, A2'-J2'). Boxed areas in A1-J1 and $\mathbf{A} 2-\mathbf{J} \mathbf{2}$ are magnified in $\mathbf{A} \mathbf{1}^{\mathbf{\prime}} \mathbf{-} \mathbf{J} \mathbf{1}^{\prime}$ and $\mathbf{A} \mathbf{2}^{\prime} \mathbf{-} \mathbf{J} \mathbf{2}^{\prime}$, respectively. Inset in $\mathbf{H} \mathbf{2}^{\prime}$ is a magnified view of the boxed area. Odor-evoked induction of IEG expression was transient and expression levels of most of the IEGs declined within 60 min of initial odorant exposure (AA 25 min, air 35 min, A3-J3). Arrows indicate GL, black arrowheads indicate M/T and green arrowheads indicate GC. AA, amyl acetate; GL, Glomerular layer; M/T, Mitral/Tufted cell layer; GC,

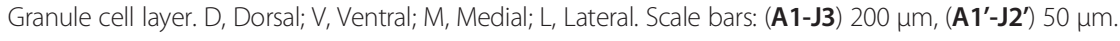

layer (black arrowhead, Figure 1A2, A2') and very dense signals were observed in the superficial aspects of the granule cell layer (green arrowhead, Figure 1A2, A2'). Similarly, we observed robust induction of Arc, c-jun, Egr1 and Junb after the odorant exposure (Figure 1). It appeared that at the activated glomeruli the Egr1 induction took place in the majority of periglomerular cells (arrows, Figure 1D2'), whereas, Arc, c-jun and Junb were upregulated in subsets of periglomerular cells (arrows, Figure 1B2', C2', G2', respectively).

In control mice signals of Egr3, Fosb, Nor1, Npas4 and Nr4a1 mRNAs were barely detectable either in the glomerular layer or in the mitral/tufted cell layer although a small fraction of granule cells were positive for these IEGs (Figure 1E1,E1', F1,F1', H1,H1', I1,I1', J1,J1'). After the amyl acetate exposure, significant induction of these five IEGs was apparent in the granule cell layer (Figure 1E2,E2', F2,F2', H2,H2', I1,I1', J2,J2') and sparse signals appeared in a few periglomerular cells and the mitral/tufted cells (Figure 1J2', data not shown).

In our subsequent experiments we analyzed induction patterns of $c$-fos, the most widely used IEG, along with Npas4 since the activity-dependent induction of Npas4 has not been previously reported in the mouse olfactory system. It was interesting to note that after $30 \mathrm{~min}$ of odor onset, Npas4 expression was robustly increased from a very low basal level and then, there was a steep decline within $60 \mathrm{~min}$ of odor onset (Figure 1I1-I3, Figure 2C). Our results indicated that expression patterns of IEGs in the mouse $\mathrm{OB}$ varied considerably at the basal condition and a single session of odorant exposure was sufficient to induce expression of the ten IEGs we examined.

\section{Different odorants produce differential responses in the mouse brain}

The OB glomeruli are spatially organized into the dorsal $\left(D_{\mathrm{I}}\right.$ and $\left.\mathrm{D}_{\mathrm{II}}\right)$ and the ventral $(\mathrm{V})$ domains and different odorants activate distinct sets of glomeruli in mice [24]. Therefore, we used two different odorants for olfactory stimulation and then observed the neuronal activation pattern by the ISH of activity-dependent genes. When we exposed mice to propionic acid, an aliphatic acid with pungent odor, we found that only a small number of glomeruli were strongly activated at the dorsomedial aspect of the anterior OB (arrowheads, Figure 3A, A') $[25,26]$. There were strong signals of $c$-fos mRNAs in periglomerular cells around the glomeruli which were presumed to be specifically activated by propionic acid. In addition, the induced expression of $c$-fos was observed in the mitral/tufted cell layer and the granule cell layer below the activated glomeruli (Figure 3A). Using optical imaging a previous study also showed that propionic acid specifically activated the anteromedial domain of the mouse OB [27]. On the other hand, amyl acetate, a strong neutral odorant, activates many glomeruli both in the dorsal and the ventral OB [25,28-30]. We also found that amyl acetate robustly induced c-fos expression in a large number of periglomerular cells, mitral/tufted cells and granule cells in both the dorsal and ventral aspects of the OB (Figure 3B). Induction of Npas4 was evident mainly in the granule cell layer of the $\mathrm{OB}$ for both propionic acid and amyl acetate (Figure 3A', B'). Accessory olfactory bulb (AOB) neurons were found to respond to the volatile, conspecific as well as allospecific odor cues $[31,32]$. Our results were in agreement with the emerging evidence for the overlapping functions of the mouse $\mathrm{OB}$ and the $\mathrm{AOB}$ in processing olfactory cues $[33,34]$. Using ISH of IEGs we found that odorants like amyl acetate and propionic acid, which are not pheromones, induced $c$-fos expression not only in the $\mathrm{OB}$ but also in the $\mathrm{AOB}$ (Figure $3 \mathrm{~A}, \mathrm{~B}, \mathrm{C}, \mathrm{D}$ ). Induced expressions of Npas4 were evident in the $\mathrm{OB}$ (Figure 3A', B') for both of these odorants although Npas4 was only slightly induced in the AOB (Figure 3C', D', insets). Therefore, these data indicate that the IEG induction patterns we observed were odorant-specific and by tracing IEG expression using ISH, it is possible to demarcate brain activities with very high spatial resolution.

\section{IEG induction demarcates the flow of olfactory information in the higher order brain regions}

Olfactory information is conveyed to and processed in a number of cortical and subcortical brain regions including the anterior olfactory nucleus $(\mathrm{AON})$, the $\mathrm{PC}$, the amygdala and the entorhinal cortex $[8,35]$. We found that the increase in the expression of these IEGs in 

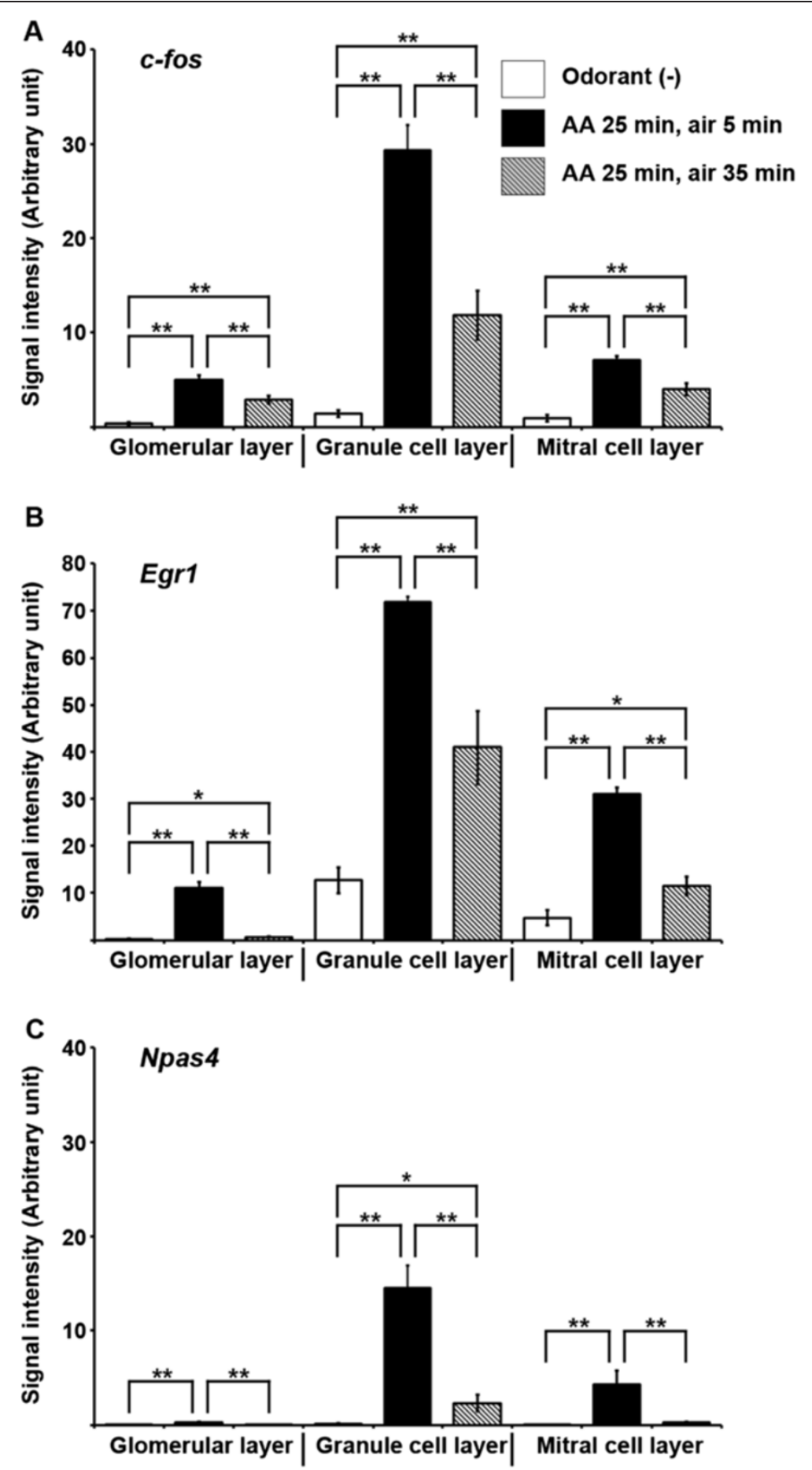

Figure 2 Quantification of odor-evoked IEG induction in the mouse OB. Signal intensity (arbitrary unit) of c-fos (A), Egr1 (B) and Npas4 (C) was calculated as the percentage of area positive for ISH signals in respective layers of the OB. Columns represented mean \pm SEM. Seven to eight bulbs (approximately from $+4.5 \mathrm{~mm}$ bregma to $+4 \mathrm{~mm}$ bregma) from two to three mice were analyzed. Student's $t$-test was performed to compare means. ${ }^{* *}$ Difference between groups was highly significant $(p \leq 0.01) .{ }^{*}$ Difference between groups was significant $(p \leq 0.05)$. 


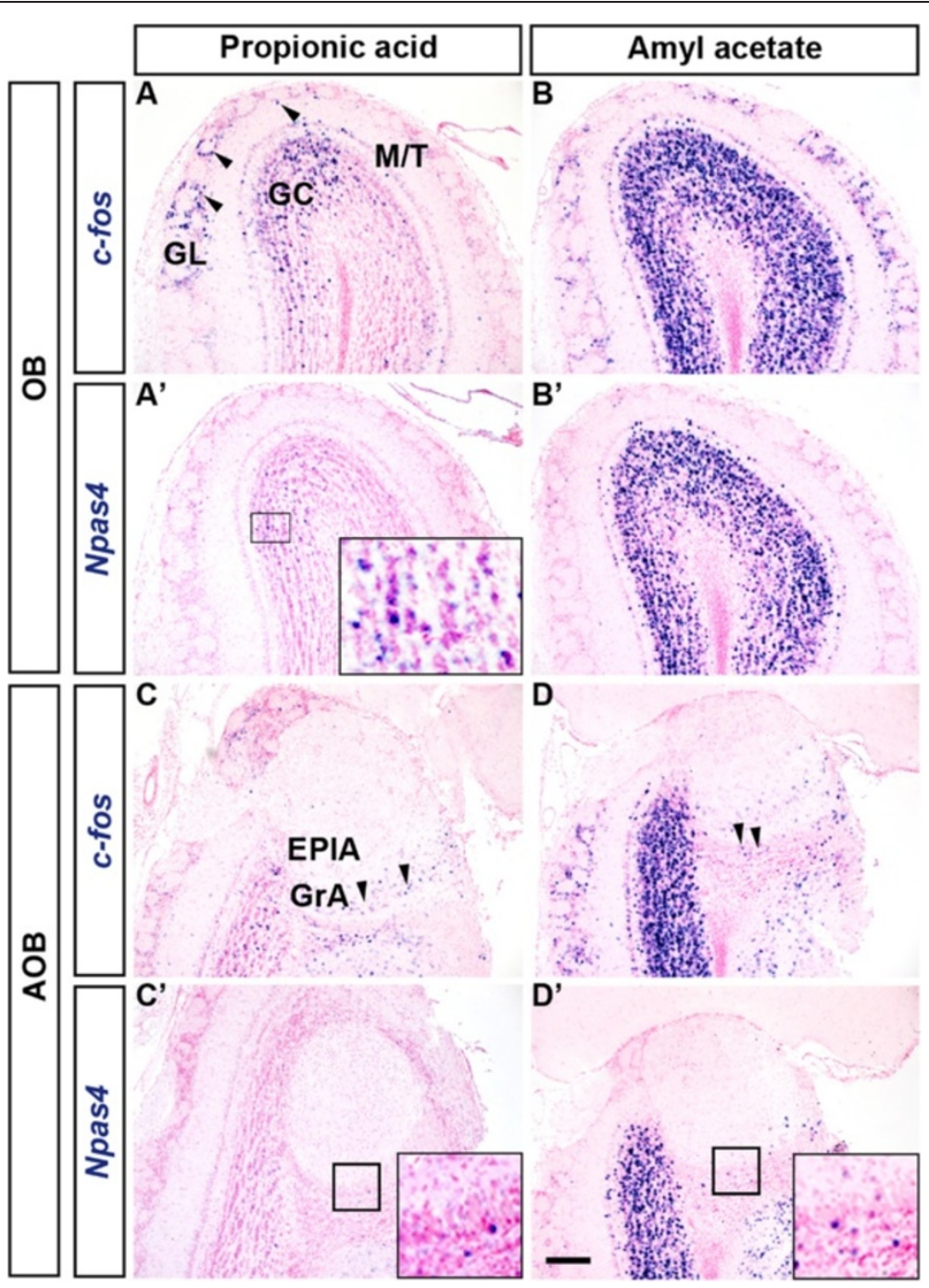

Figure 3 Comparison of IEG induction patterns in response to two different odorants. Mice were sacrificed after the 30-min continuous exposure to the test odorant. (A, $\mathbf{A}^{\prime}$ ) Propionic acid activated several glomeruli specifically in the dorsal OB (arrowheads in A). Induced expression of Npas4 was observed only in the granule cell layer ( $A^{\prime}$, inset). (B, $\left.\mathbf{B}^{\prime}\right)$ A large number of glomeruli were activated by amyl acetate. Npas4 induction was apparent only in the granule cell layer (B'). (C-D') Patterns of IEG induction in the AOB after odorant exposure. Arrowheads indicate $c-f o s$ induction in the granule cell layer of the AOB (C, D). Only a slight induction of Npas4 was observed in the AOB (C', D', insets). GL, Glomerular layer; M/T, Mitral/Tufted cell layer; GC, Granule cell layer; GrA, Granule cell layer of the AOB; EPIA, External plexiform layer of the AOB. Scale bar: $200 \mu \mathrm{m}$.

AON (arrows, Figure 4A-B') paralleled to the activation of $\mathrm{OB}$ neurons. It is known that in the $\mathrm{PC}$ pyramidal neurons receive direct input from mitral/tufted cells of the OB. Consequently, odorant exposure activates unique but overlapping subsets of neurons in the PC [36]. As expected, we observed odorant-induced increase in expression of IEGs in the layer $2 / 3$ of the PC where cell bodies of pyramidal neurons are located (arrows, Figure 4D, D').

Owing to the intimate connection between olfaction and memory, the hippocampus has been of great interest for studying olfactory memory. We found that the exploration of odor cues only for a brief period significantly induced the expression of several IEGs in the mouse hippocampus (Figure 4E-F', data not shown). Our ISH data clearly indicate that odor stimulus not only triggered the robust induction of IEGs in the mouse OB but also conspicuously increased the expression of these genes in various brain regions which are involved in olfactory signal processing.

\section{Individual differences in sexual stimuli-induced neuronal activities in Cnga2-null male mice}

It is interesting that most Cnga2-null male mice show neonatal mortality, general anosmia and deficits in sexual behaviors, however, a small number of the surviving 


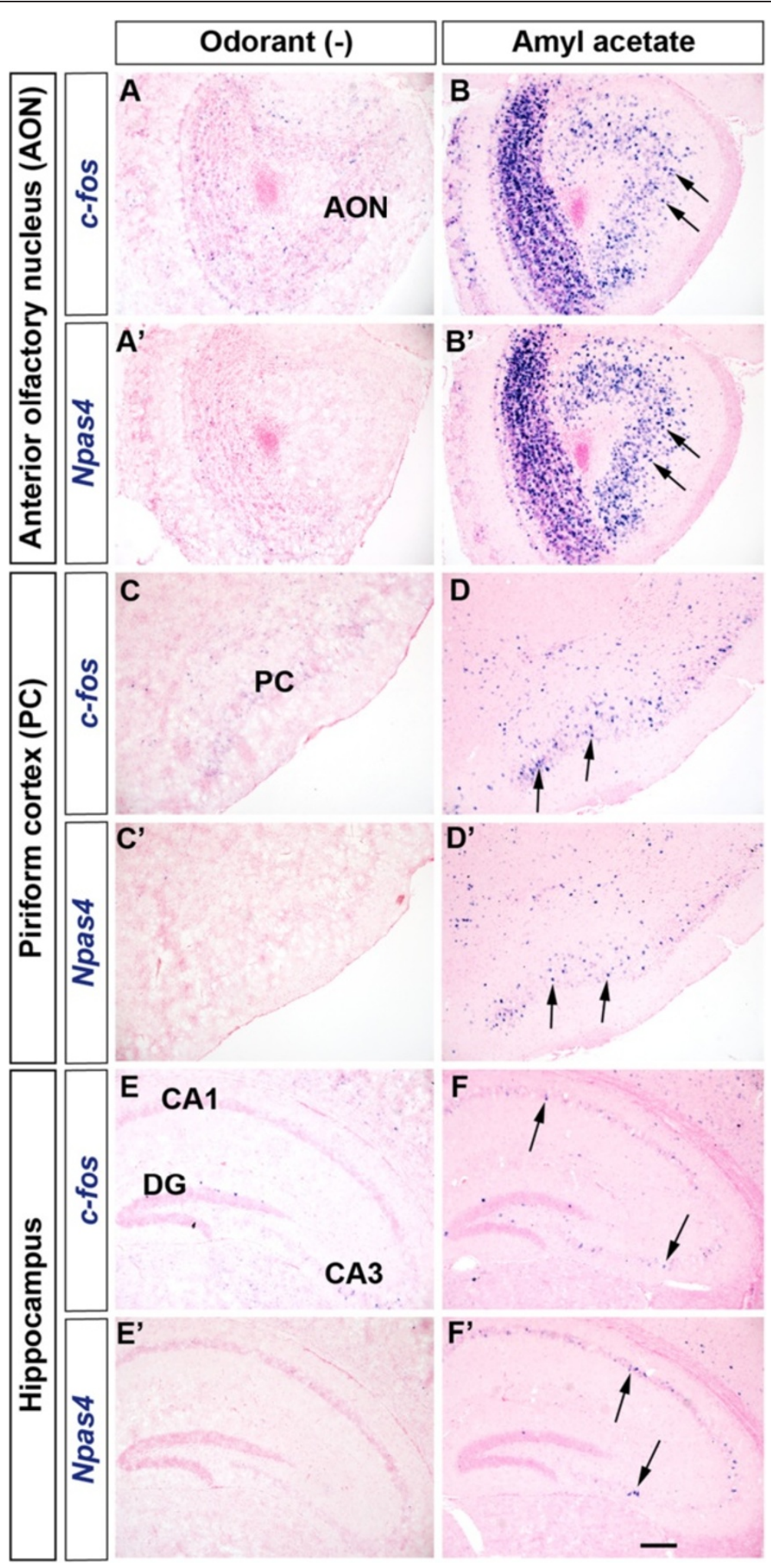

Figure 4 Odorant exposure induced activity-dependent gene expression in different brain regions. Odorant exposure induced expression of $c$-fos $(\mathbf{A}-\mathbf{F})$ and Npas4 ( $\left.\mathbf{A}^{\prime}-\mathbf{F}^{\prime}\right)$ in the AON (arrows, A-B'), the PC (arrows, C-D') and the hippocampus (arrows, E-F'). DG, Dentate gyrus. Scale bar: $200 \mu \mathrm{m}$. 
male mutants can mate successfully $[19,20]$. We tested the hypothesis whether the positive sexual behavior observed in some Cnga2-null male mice is correlated with a concurrent activation of the main olfactory system. In the home cage, mice experience many ambient odorants which are known to produce dense $c$-fos mRNA signals in olfactory structures (Figure 5A1) [28]. First we checked the extent of IEG expression by such ambient odorants in the $\mathrm{OB}$ of male Cnga2-null mice. Figure 5A depicts clear differences between the mutant and the wild type littermates in $c$-fos induction patterns when the animals were taken from the home cage immediately before sacrifice. In the $\mathrm{OB} c$-fos expression level was very low in mutants compared to that of wild type littermates (Figure 5A1,A1'). However, we observed strong $c$-fos signals in a few isolated glomeruli in the mutant OB (Additional file 1: Figure S1B3). Expectedly, c-fos mRNA signals were practically absent in the AOB (Figure 5A2,A2') in both the wild type and the mutant mice. Baker et al. (1999) and Lin et al. (2004) previously reported dramatically reduced tyrosine hydroxylase $(\mathrm{TH})$ immunoreactivity, a marker for afferent activity, in most of the typical OB glomeruli in CNGA2-deficient mice $[21,37]$. Nevertheless, in mutant mice strong TH staining was evident in a number of discrete glomeruli including the necklace glomeruli which are found at the posterior $\mathrm{OB}$ and are innervated by OSNs expressing a specific guanyl cyclase (GC-D) and a phosphodiesterase, PDE2 $[21,37,38]$. In Cnga2-null mice we observed that Th mRNA expression was also significantly downregulated in most of the glomeruli while strong expression was retained only in a small number of glomeruli, presumably the necklace glomeruli (Additional file 1: Figure S1B1, B2). Since CNGA2 is expressed in almost all typical glomeruli, but not in necklace glomeruli which use cGMP as a second messenger instead of cAMP for olfactory signal transduction, our results supported the view that the cAMP pathway plays the key role for activation of the majority of ORNs and that olfaction is highly attenuated in the Cnga2-null mice $[19,21,37]$.

To check whether the main olfactory system in Cnga2-null male mice is unable to detect conspecific cues from female mice, we exposed Cnga2-null male mice and wild type male littermates to estrous female mice. Wild type mice started chemoinvestigation (sniffing/licking) of the female anogenital regions almost instantly (Additional file 2: Movie S1) and did mounting (attempted or successful) within the first 3 min of exposure. Consistent with a previous report [20], the lack of sexual behaviors was clearly apparent in Cnga2-null male mice (Additional file 2: Movie S1). Most of the Cnga2-mutant mice (7 out of 9 mice) did not initiate the exploration of female anogenital or facial regions.
Instead, mutant male mice exhibited only occasional sniff-like behaviors often resembling grooming behaviors. We did not observe any mounting behavior in the Cnga2- null male mice during presentation of female mice for $30 \mathrm{~min}$ (data not shown). Nonetheless, sniffing/ sniff-like behavior was observed within the first $3 \mathrm{~min}$ of exposure both in wild type mice and Cnga2-null mice (Additional file 2: Movie S1). Neuronal activation in the $\mathrm{OB}$ was strikingly lower in those mutant mice (Figure 5B1', B2') compared to wild type male littermates (Figure 5B1, B2). Interestingly, a few (2 out of 9) Cnga2null male mice showed positive sexual behaviors which were practically indistinguishable from the wild type behaviors. Those mutants started chemoinvestigation (sniffing/licking) of the female anogenital areas almost instantly and showed mounting behaviors even within the first minute of exposure (Additional file 3: Movie S2). Despite the arousal of sexual behaviors the strong glomerular activation observed in the $\mathrm{OB}$ of wild type mice (arrowheads, Figure 5B1) was absent in those mutants. Nevertheless, $c$-fos and other IEGs were induced in a small fraction of $\mathrm{OB}$ granule cells in the mutant mice (arrows, Figure 5B1", B2"); albeit the induction was noticeably lower than that in wild type mice (arrows, Figure 5B1, B2).

Conspecific odor cues considerably induced expression of IEGs in the mouse AOB (arrows, Figure 5B3, B4, compare Figure 5A2). Even in the Cnga2-null male mice, a substantial IEG induction was observed in the $\mathrm{AOB}$ after exposure to the female stimuli (arrows, Figure 5B3", B4"). Consistently, IEG induction was lower in the mutants which did not show any apparent sexual behavior (arrows, Figure 5B3-B4").

We further analyzed neuronal activation in other brain regions of the Cnga2-null male mice which were exposed to female mice (Figure 5B5-B8"). We found that induction of $c$-fos expression was very low in the PC of the Cnga2-null mice which did not show sexual behaviors (arrows, Figure 5B5, B6"). In rodents, exposure to estrous odors increased Fos immunoreactivity in the medial amygdala [39] and the medial amygdala was found to regulate attraction to female odor cues [40]. We found that both in wild type mice and Cnga2 mutants which interacted with female mice, a conspicuous induction of IEGs occurred in the posterodorsal part of the medial amygdaloid nucleus (MePD) (arrows, Figure 5B7, B8, B7", B8"). Expectedly, the IEG induction in the MePD was much lower in the Cnga2-null male mice which did not show sexual behaviors (arrows, Figure 5B7, B8'). These results provide the evidence that tracing IEG induction by ISH can detect differences in brain activities, with high spatial sensitivity, which correspond to individual behavioral differences. These results also indicate that the lack of amygdaloid 


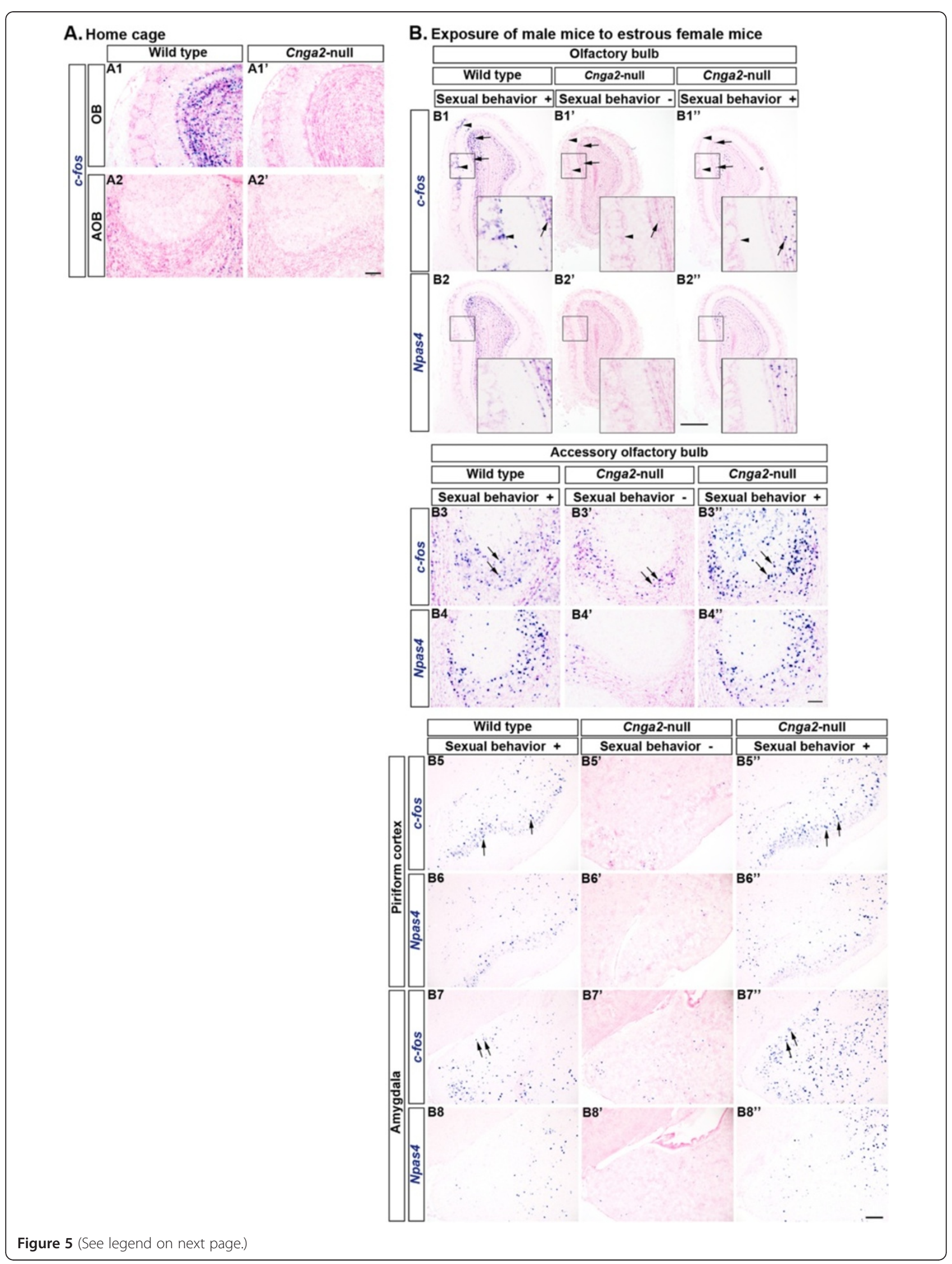


(See figure on previous page.)

Figure 5 Individual differences in induction of activity-dependent genes in Cnga2-null mice after exposure to female mice.

A. Expression of $c$-fos in mice which were sacrificed from their home cages without any odorant exposure. Significantly reduced expression levels of $c$-fos were observed in the $\mathrm{OB}\left(\mathrm{A} 1^{\prime}\right)$ and $\mathrm{AOB}\left(\mathrm{A} 2^{\prime}\right)$ of $C$ nga2-null male mice compared to that of wild type male littermates ( $\mathrm{A} 1$, $\mathrm{A} 2$, respectively). B. Induction of $c$-fos expression in male mice which were exposed to estrous female mice. Arrowheads indicate the glomerular layer and arrows indicate the granule cell layer. Sexual stimulation by female mice induced expression of IEGs in the wild type OB (B1, B2). IEG induction was almost absent in the Cnga2 mutants which did not show sexual behaviors (B1', B2'). IEG induction occurred in the OB, mainly in the granule cell layer, of the Cnga2-null male mice which showed sniffing and mounting behaviors (B1", B2"). Insets in (B1-B2") show magnified views of the boxed areas. IEG induction occurred in the AOB of male mice exposed to female mice (arrows, B3-B4"). (B5-B6") Induction of IEGs in the PC (arrows) after exposure to female mice. Both in the wild type mice (B5, B6) and the mutants (B5", B6") which showed sexual behaviors, expression of IEGs was induced in the PC. IEG induction did not occur in the PC of Cnga2-null mice (B5', B6') which did not show sexual behaviors. (B7-B8") Induction of IEGs in the MePD (arrows) after exposure to female mice. Both in the wild type mice (B7, B8) and the mutants (B7", B8") which showed sexual behaviors, expression of IEGs was induced in the MePD. The IEG induction did not occur in the MePD of Cnga2-null mice (B7', B8') which did not show sexual behaviors. Scale bars: (A1-A2' and B3-B4") $100 \mu \mathrm{m},\left(B 1-B 2^{\prime \prime}\right) 500 \mu \mathrm{m}$, (B5-B8') $200 \mu \mathrm{m}$.

activation following presentation of the female sexual stimuli may contribute to the diminished sexual behaviors observed in the majority of Cnga2-null male mice.

\section{TMT exposure activates the OB in Cnga2-null mice without eliciting avoidance}

We then sought to know if a strong odorant, amyl acetate, can trigger glomerular activation in the Cnga2-null $\mathrm{OB}$ in our experimental conditions. To our surprise, we observed robust activation of a large number of glomeruli by the emergence of dense $c$-fos mRNA signals in periglomerular cells and in the mitral/tufted cell layer and the granule cell layer below the activated glomeruli (Figure 6A). Interestingly, c-fos induction was stronger in the mutant $\mathrm{OB}$, predominantly in the ventrolateral aspects, compared to that in the wild type OB (Figure 6A).

We next exposed the Cnga2-null mice and wild type littermates to the predator odor TMT which produces avoidance behaviors in rodents [41]. For behavioral analyses we introduced a piece of filter paper soaked with distilled water or TMT in the mouse cage and observed avoidance behaviors such as stretch attend posture (the animal approaches and sniffs the filter paper with flat back and stretch neck) and withdrawal (the mouse approaches without contact and immediately withdraws from the stimulus) and non-avoidance behaviors such as crouching over object and catching (the mouse takes the filter paper in its mouth) [42]. TMT-induced avoidance behaviors, as quantified by the events of withdrawal, were present in wild type mice but practically absent in Cnga2-null mice (Figure 6B1, Additional file 4: Movie S3). In contrast, Cnga2-null mice showed non-avoidance behaviors including increased investigation and crouching over the TMTsoaked filter paper unlike their wild type littermates (Figure 6B1, Additional file 4: Movie S3). We then checked IEG expression levels in the mice which were exposed to TMT for $30 \mathrm{~min}$. TMT strongly induced $c$-fos
mRNA expression in the wild type OB (Figure 6B2). Notably, we also observed strong induction of IEGs in the $\mathrm{OB}$ and the AOB of Cnga2-null mice (Figure 6B2', B3', respectively) despite the absence of predator odor-induced avoidance response (Figure 6B1). Taken together, our results suggest that the predator odor TMT can strongly activate the main olfactory system in Cnga2-null mice although such activation seemed to fail to produce typical avoidance response.

\section{Discussion}

\section{Detection of neuronal activity using ISH of IEGs}

Tracing IEG expression has been proved to be a very reliable and powerful tool for visualization of neuronal activities. In this study we compared mRNA expression patterns of ten IEGs using the ISH method. We found that these IEGs, which included both the transcription factors and effectors, were expressed at low levels in different brain regions in mice at the basal condition (Figure 1). We observed differential expression patterns of these activity-dependent genes in different cell layers of the mouse OB. Interestingly, all these genes were induced significantly in the $\mathrm{OB}$ after exposure of the mouse to a given odorant, presumably due to stimulation of the olfactory sensory pathway. However, an increasing number of studies indicate that centrifugal innervation can substantially modulate odor processing in the OB [11-14]. We observed IEG induction in spatially restricted regions in response to propionic acid whereas amyl acetate triggered global induction in the OB (Figures 1, 2 and 3). Therefore, we cannot rule out the possibility that central inputs had role in activation of a large number of $\mathrm{OB}$ granule cells we observed in some cases, for instance, after amyl acetate exposure.

The basic helix-loop-helix (bHLH)-PAS transcription factor Npas4 has been previously identified as a critical factor in regulation of inhibitory synapse development on excitatory neurons [43] and recent reports indicate that the Npas4 gene is involved in learning and memory 


\section{A. Exposure to amyl acetate}

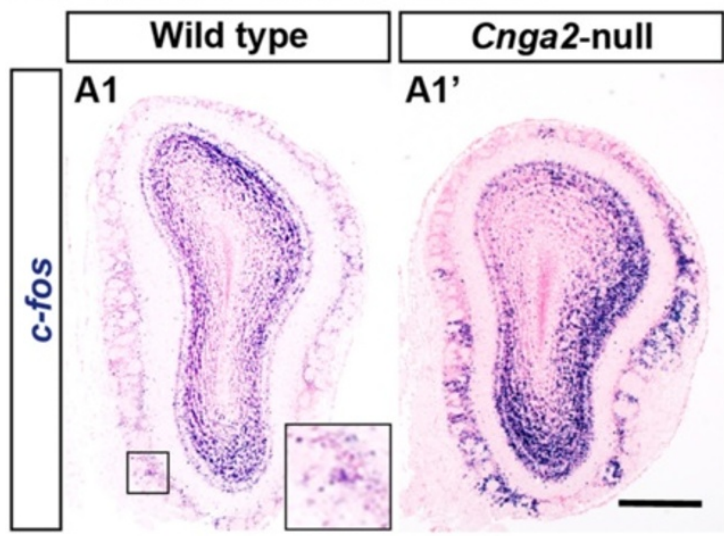

\section{B. Exposure to TMT}

B1 $\square$ Wild type $\square$ Cnga2-null
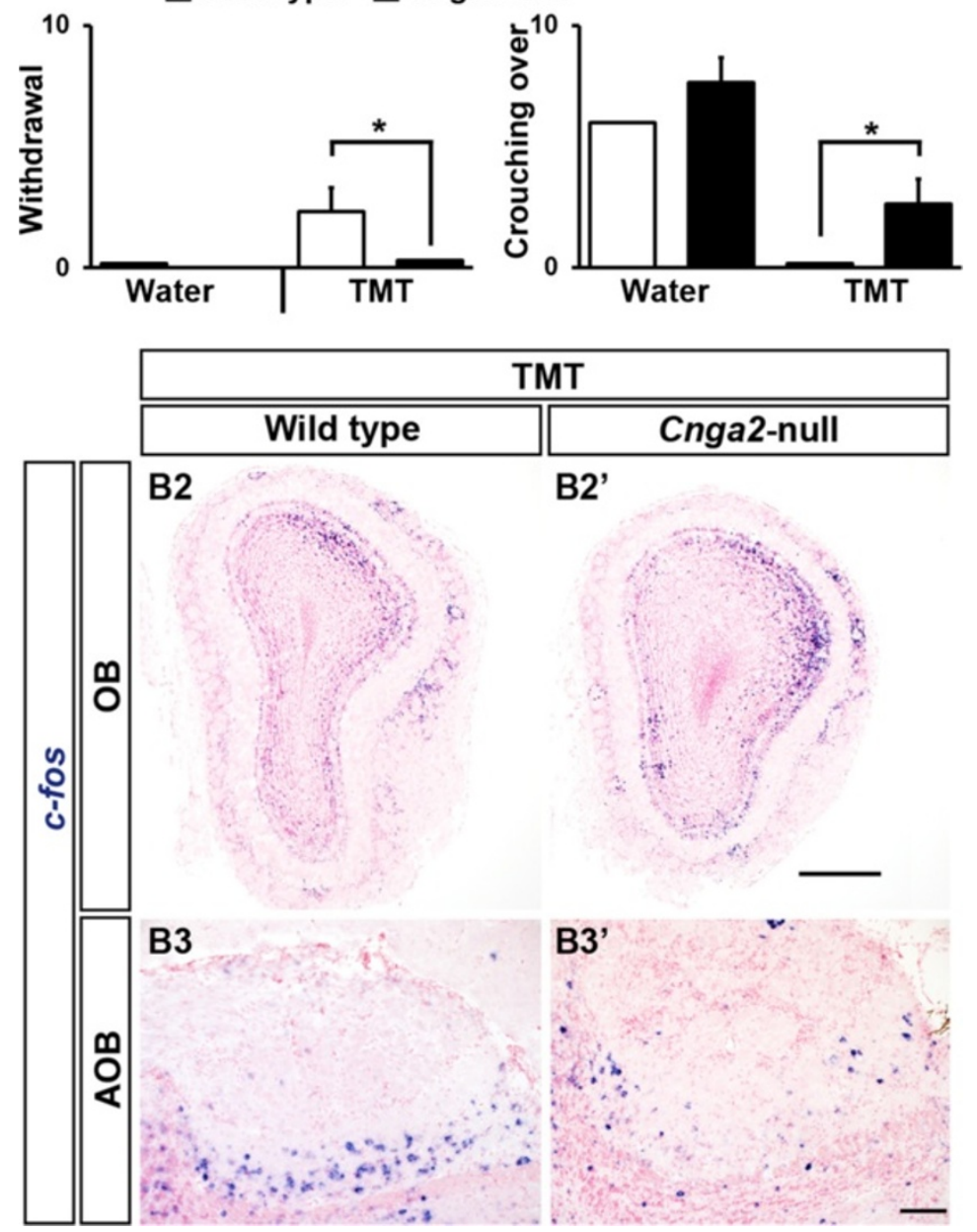

Figure 6 Neuronal activation in response to amyl acetate and TMT in Cnga2-null mice. A. A neutral odorant, amyl acetate, robustly induced $c$-fos expression in the OB in both wild type (A1) and Cnga2-null (A1') mice. Inset in A1 shows magnified view of the boxed area. B. Responses of mice after presentation of TMT, a predator odor from fox. TMT-induced avoidance behaviors were present in wild type mice but absent in Cnga2-null mice (number of withdrawal, B1 left). Unlike wild type mice, Cnga2-null mice showed increased investigating behaviors for TMT (number of crouching over, B1 right). After exposure to TMT for 30 min, expression of c-fos was induced in both wild type and Cnga2-null mice in the $\mathrm{OB}\left(\mathrm{B} 2, \mathrm{~B}^{\prime}\right.$, respectively) and the $\mathrm{AOB}$ (B3, B3', respectively). Scale bars: (A1, A1', B2, B2') $500 \mu \mathrm{m},\left(B 3-B 3^{\prime}\right)$ 100 $\mu$ m. 
[44,45]. Expression of Npas4 mRNA was found to be increased by membrane depolarization in vitro and by 1 $\mathrm{h}$ light stimulation in vivo in the visual cortex of darkreared mice [43]. Our in vivo results indicate that the basal expression of Npas4 is very low in the mouse OB and a brief olfactory stimulation is sufficient to induce this gene rapidly and transiently in the mouse brain (Figure 1I1-I2', Figure 2).

We found that the induction of both $c$-fos and Egr1 took place in a greater number of cells in the OB compared to that of other IEGs, although the basal expression of Egr1 was slightly higher (Figure 1A1-A2', D1D2'). The rapid induction and the wider coverage of $c$-fos expression in different subtypes of cells explain the versatile use of $c$-fos in IEG mapping. Nevertheless, a different IEG may be suitable in a particular experimental setup depending on the neuronal cell type or the stimuli under consideration. For instance, in a recent study Isogai et al. (2011) compared the expression of several IEGs in mouse vomeronasal organ and found that the Egr1, but not the $c$-fos, was induced robustly following sensory stimulation [46]. Likewise, our results suggest that Npas4 would be a suitable marker for identifying activation of granule cells in the mouse OB.

\section{Sexual behaviors in Cnga2-null male mice}

Previous studies indicated that inactivation of the main olfactory system considerably affects sexual behaviors in male mice [34]. This view has been substantiated by the observation of significant deficits in sexual behavior in male Cnga2-null mice [20] since CNGA2 is essential for signal transduction in most of the MOE neurons $[15,47,48]$. Consistently, we observed that in Cnga2-null male mice female sexual stimuli failed to activate the $\mathrm{OB}$ and did not initiate sexual behaviors although the IEGs were significantly induced in the AOB. However, there are individual differences and in a longer mating assay Mandiyan et al. (2005) found that a female mouse cohabitating with mutants was plugged once and gave birth [20]. We also observed significant sexual arousal in a few Cnga2-mutant male mice (see results). This raised the possibility that a CNGA2-independent signaling pathway(s) can activate the $\mathrm{OB}$ to initiate sexual behaviors. Our study supports this idea, although it contradicts with the suggestion made by Mandiyan et al. (2005) that the sub-population of MOE neurons which use alternative signaling pathway cannot initiate mating responses [20]. We observed induction of IEGs in a significant number of $\mathrm{OB}$ granule cells and mitral/tufted cells in the Cnga2-null mice which initiated mating behaviors when exposed to estrous female mice (Figure 5B1", B2"). Previously it has been suggested that the transient receptor potential channel M5 (TRPM5)expressing OSNs which project to the ventral $\mathrm{OB}$ are involved in pheromone signaling in CNGA2-defective mice [49]. In the Cnga 2 mutants we observed stronger induction of IEGs in the dorsal OB (arrows, Figure 5B1", B2") in addition to the weaker ventral induction. Therefore, another set of OSNs targeting glomeruli in the dorsal $\mathrm{OB}$ may participate in transmitting olfactory signals sufficient to initiate mating behaviors in CNGA2deficient mice. However, we cannot rule out the possibility that the sexual arousal observed in a few Cnga2-null male mice might have been initially triggered by sensory modalities other than olfaction, for instance, visual and/ or auditory stimuli, which activated centrifugal inputs to the $\mathrm{OB}$ and induced IEGs predominantly in the granule cell layer (Figure 5B1",B2") secondary to the activation of the accessory olfactory system (Figure 5B3",B4").

\section{Strong glomerular activation in the OB of anosmic Cnga2- null mice}

Using ISH we compared the expression level of IEGs in the olfactory system of Cnga2-null mice and wild type control mice. We found that the environmental olfactory stimuli in usual laboratory conditions produce significant neuronal activities in the $\mathrm{OB}$ of wild type mice whereas the IEG expression levels were remarkably lower in the OB of Cnga2-null mice (Figure 5A).

Previously Lin et al. (2004) found that CNGA2deficient mice detected some odorants and the authors suggested cAMP-independent pathways for the observed responses [21]. Later, Munger and colleagues (2007) demonstrated that GC-D neurons, which lack CNGA2 and several other components of the canonical odor transduction pathway and axons of which innervate the necklace glomeruli, can utilize a cGMP-dependent signaling cascade for chemosensory transduction [38]. In those previous studies only a small subset of glomeruli including the necklace glomeruli were found to be activated by the suggested CNGA2-independent signaling pathway(s) $[21,38]$. In contrast, we observed that amyl acetate robustly induced $c$-fos mRNA expression in the $\mathrm{OB}$ of Cnga2-null mice, notably at the ventrolateral $\mathrm{OB}$, in a large number of glomeruli which could include, but apparently not limited to, the necklace glomeruli (Figure 6A1'). We also observed that TMT, a predator odor from fox which produces fear responses in wild type mice, induced the expression of IEGs very strongly in the OB (Figure 6B2') without eliciting any obvious fear response in Cnga2-null mice. Previously Kobayakawa et al. (2007) found that the mice in which the OSNs were ablated specifically in the dorsal olfactory epithelium lacked innate fear response to TMT even though the mice could detect the odorant [30]. They proposed the existence of hard-wired circuits in the mammalian olfactory system for processing innate responses [30,50]. Our results indicate that a CNGA2- 
dependent signaling pathway may be essential for the mouse olfactory circuits to initiate innate fear responses.

In our experiments odorant concentrations were high since pure liquid odorants were introduced in the mouse cage. Previously it has been suggested that a cAMP-independent pathway(s) contributed in the EOG responses observed in the MOE of Cnga2-null mice exposed to odorants at relatively higher concentrations [21]. Olfactory neurons expressing TRPM5 can detect the chemicals involved in animal communication and TRPM5-expressing OSNs project mainly to the ventral OB [49]. Indeed, we observed strong $c$-fos induction in a large number of glomeruli mainly in the ventral $\mathrm{OB}$ in Cnga2-null mice exposed to amyl acetate (Figure 6A1'). In addition, a predator odor TMT strongly activated spatially segregated glomeruli in mutants (Figure 6B2'). However, in addition to direct peripheral inputs via OSNs, there could be other possibilities which might contribute to the odor-induced glomerular activation observed in Cnga2null mice. Centrifugal inputs are known to modulate neuronal activities in the rodent $\mathrm{OB}$, predominantly in the granule cell layer [11-14] and might have contributed in the odorant-induced IEG inductions observed in the present study. Although Cnga2-null mice appeared normal in several behavioral tests including grooming [20,51], the size of the $O B$ is apparently smaller in the mutants and alteration in brain development has been suggested [37]. Schaefer et al. (2002) reported collateral innervation of the olfactory epithelium and $\mathrm{OB}$ by some trigeminal ganglion cells in rats $[52,53]$. Trigeminal activation was found to inhibit olfactory responses [52,54] and thus, the role of trigeminal activation might be insignificant for IEG induction in our experiments. It was interesting that amyl acetate-induced $c$-fos expression was stronger in CNGA2-deficient mice compared to wild type mice and may suggest impaired peripheral adaptation in glomeruli [55] and/or reduced presynaptic inhibition of OSNs [56] in mutants although further studies will be needed to decode the observed phenomena. However, without the CNGA2 subunit there is no functional CNG channel for transduction of olfactory signals in most of the MOE neurons $[47,48]$. Together, our data provide support for the idea that in addition to the CNGA2-dependent pathway other alternative signaling pathways participate in signal transduction in the mouse main olfactory system.

\section{Conclusions}

In this study we performed ISH analysis to confirm odor-evoked induction of a number of IEGs and show for the first time that in vivo olfactory stimulation can strongly induce the neuronal IEG Npas4 in the mouse OB. We provide evidence that some odorants can produce strong glomerular activation in the Cnga2-null mice in which the olfactory cAMP signaling pathway is almost completely perturbed suggesting involvement of CNGA2-independent signaling pathway(s) for processing olfactory information. Furthermore, our findings advocate that the ISH probe set we established for IEG tracing can be very useful to visualize neuronal activity with high spatial resolution.

\section{Methods}

\section{Mice}

Pregnant ICR mice were purchased from Japan SLC, Inc. Cnga2 mutant mice (JAX Mice stock number 002905) originated from Dr. John Ngai lab [19] were kindly provided by Dr. Hitoshi Sakano [57]. Since the Cnga2 gene localizes on $\mathrm{X}$ chromosome, Cnga2-null male mice were obtained by crossing wild type male mice and heterozygous female mice. Although most of the Cnga2-null mice die during early postnatal period, a few rare survivors can grow until adulthood. At least three wild type mice and two Cnga2-null mice were analyzed for each condition. For Cnga2-null mice, wild type male littermates were used as controls. All measures were taken to minimize pain or discomfort to the mice. All animal procedures were carried out following the guidelines of Kumamoto University and Niigata University.

\section{Odorant exposure}

Mice were exposed to overhead airflow for $2 \mathrm{~h}$ in a clean cage without food and water before the odorant exposure. Undiluted odorants were poured into a $1.5-\mathrm{ml}$ microcentrifuge tube attached to the wall of the mouse cage. Following odorants were used: Amyl acetate/Pentyl acetate (60 $\mu$ l, Wako, Japan), Propionic acid (60 $\mu$ l, Sigma-Aldrich) and 2, 3, 5-trimethyl-3-thiazoline (TMT) (30 $\mu$ l, Contech, Canada). If not mentioned otherwise, mice were exposed to the test odorant continuously for $30 \mathrm{~min}$ and sacrificed immediately. For analyzing IEG induction a mouse was tested only once to minimize effects of learning.

\section{Mating assay}

Mice were habituated in the test cage for $2 \mathrm{~h}$ as described above. A wild type estrous female mouse was presented for $30 \mathrm{~min}$ to an individual test mouse with no prior sexual experience. Sexual behaviors (sniffing, mounting and intromission) of the male mouse were observed and the test mouse was sacrificed at the end of the 30-min exposure. Sexual behaviors were considered to be present if the test mouse did mounting (attempted/successful) at least once during the 30-min period.

\section{TMT-induced avoidance test}

Mice were habituated for approximately $10 \mathrm{~min}$ in the test cage $(30.5 \times 20 \times 13 \mathrm{~cm}$, without food, water, and lid) followed by the 3 -min test period. Then a piece of 
filter paper $(\sim 2 \mathrm{~cm} \times 2 \mathrm{~cm})$ soaked with distilled water (control) or TMT was introduced at one end of the cage. Avoidance and non-avoidance behaviors were observed [42]. Avoidance was counted as the number of events of withdrawal (the mouse approaches the odorant without contacting it, immediately withdrawing from it) and non-avoidance behavior was counted as the number of events of crouching over (the mouse investigates and crouches over the filter paper) [42]. Three Cnga2-null male and 3 wild type littermate male mice were used for this test. The test was done twice with intervals of at least 3 days.

\section{In situ hybridization (ISH)}

Sections were prepared from frozen tissue blocks and ISH was performed as described [58]. Briefly, 20- $\mu \mathrm{m}$ coronal tissue sections were digested with Proteinase $\mathrm{K}(1 \mu \mathrm{g} / \mathrm{ml})$ for $75 \mathrm{~min}$ and post-fixed in $4 \%$ PFA. After prehybridization, specimens were incubated overnight at $65^{\circ} \mathrm{C}$ with digoxigenin (DIG)-labeled riboprobes (Information on ISH probes is provided in Additional file 5: Table $\mathrm{S} 1)$. Following washes, blocking was done by $1 \%$ sheep serum, $1 \%$ bovine serum albumin (BSA) and $0.1 \%$ Triton X-100 in phosphate-buffered saline (PBS). Afterwards, samples were incubated overnight at $4^{\circ} \mathrm{C}$ with alkaline phosphatase-conjugated anti-DIG antibody (1:2000, Roche Diagnostics, Germany). Sections were washed in MABT (100 mM Maleic acid, $150 \mathrm{mM}$ $\mathrm{NaCl}, 0.1 \%$ Tween 20) and then in alkaline phosphatase buffer (100 mM NaCl, $100 \mathrm{mM}$ Tris-HCl, pH 9.5, $50 \mathrm{mM} \mathrm{MgCl}_{2}, 0.1 \%$ Tween 20, $5 \mathrm{mM}$ Levamisole). Tissue sections were treated with NBT/BCIP (Roche) mixture at room temperature in dark for color development. After ISH staining, sections were counterstained by nuclear fast red.

\section{Quantification of IEG expression levels}

Images of stained coronal sections of the olfactory bulb were captured with an Olympus microscope and digital camera system (BX53 and DP72; Olympus, Tokyo, Japan). Quantification was performed using Adobe Photoshop CS5 Extended (version 12.0.4 × 64, Adobe Systems Incorporated) adapting the techniques described previously $[59,60]$. The glomerular layer, the mitral cell layer and the granule cell layer were selected separately by the Lasso tool. Total number of pixels and the number of pixels positive for ISH signals were counted using the Histogram tool. Signal intensity (arbitrary unit) of IEGs was calculated as the percentage of area positive for ISH signals in respective layers of the olfactory bulb. Data were plotted in column charts where columns represented mean \pm SEM. Seven to eight bulbs (approximately from + $4.5 \mathrm{~mm}$ bregma to $+4 \mathrm{~mm}$ bregma) from two to three mice were analyzed.

\section{Statistical analysis}

Student's $t$-test was performed to compare means. Difference between groups was considered highly significant $\left({ }^{* * *}\right)$ when $\mathrm{p} \leq 0.01$ and significant $\left({ }^{*}\right)$ when $\mathrm{p} \leq 0.05$.

\section{Additional files}

\begin{abstract}
Additional file 1: Figure S1. Strong residual activity at the necklace glomeruli in Cnga2-null mice. Figure shows horizontal sections of the OB. Expression of Th, a marker of afferent activity, was significantly reduced in most of the OB glomeruli in Cnga2-null mice (B1) compared to that of wild type mice (A). However, strong Th expression was observed in a small number of glomeruli (B1, inset), presumably the necklace glomeruli which express Pde2 (B2, inset). In Cnga2-null mice $c$-fos expression was almost absent in the $O B$. However, strong $c$-fos signals appeared in a few glomeruli (B3, inset). Scale bar: $200 \mu \mathrm{m}$.
\end{abstract}

Additional file 2: Movie S1. Behavioral responses of wild type and Cnga2-null male mice after presentation of estrous female mice.

Additional file 3: Movie S2. Positive sexual behavior in Cnga2-null male mice.

Additional file 4: Movie S3. TMT-induced avoidance test.

Additional file 5: Table S1. Information on ISH probes.

\section{Abbreviations}

ACIII: Adenylyl cyclase type III; AOB: Accessory olfactory bulb; AON: Anterior olfactory nucleus; Cnga2: Cyclic nucleotide-gated channel subunit A2; EOG: Electro-olfactogram; $G_{\text {olf: }}$ Olfaction-specific G protein; IEG: Immediate early gene; ISH: In situ hybridization; MePD: Dorsomedial part of the medial amygdaloid nucleus; MOE: Main olfactory epithelium; OB: Olfactory bulb; OR: Olfactory receptor; OSN: Olfactory sensory neuron; PC: Piriform cortex; TMT: 2, 3, 5-trimethyl-3-thiazoline.

\section{Competing interests}

The authors declare that they have no competing interests.

\section{Authors' contributions}

AKB carried out the experiments, performed statistical analysis and drafted the manuscript. KW participated in the design of the study, and helped to analyze the data and to draft the manuscript. MY participated in the design of the study and revised the manuscript critically. NT participated in the design of the study and revised the manuscript. HT conceived of the study, and participated in its design and coordination and helped to draft the manuscript. All authors read and approved the final manuscript.

\section{Acknowledgements}

We thank Dr. John Ngai, Dr. Nobuko Inoue and Dr. Hitoshi Sakano for Cnga2null mice, Dr. Daniel Lévesque and Dr. Joseph Beavo for Nor1 and Pde2 plasmids, respectively and Ms. Mari Miyamoto for technical assistance. The authors are thankful to the animal facilities at Kumamoto University and Niigata University for maintaining the mouse colonies. This work was supported by Grants from JST PRESTO and Global COE Program (Cell Fate Regulation Research and Education Unit), MEXT, Japan. AKB is supported by the Japanese Government (Monbukagakusho: MEXT) Scholarship.

\section{Author details}

${ }^{1}$ Department of Morphological Neural Science, Graduate School of Medical Sciences, Kumamoto University, Kumamoto, Japan. ${ }^{2}$ Division of Neurobiology and Anatomy, Graduate School of Medical and Dental Sciences, Niigata University, Niigata, Japan. ${ }^{3}$ Department of Physiology, Graduate School of Medicine, University of Tokyo, Tokyo, Japan. ${ }^{4}$ RRESTO, Japan Science and Technology Agency (JST), Kawaguchi, Saitama, Japan.

Received: 4 July 2012 Accepted: 31 October 2012

Published: 5 November 2012 


\section{References}

1. Flavell SW, Greenberg ME: Signaling mechanisms linking neuronal activity to gene expression and plasticity of the nervous system. Annu Rev Neurosci 2008, 31:563-590.

2. Norlin EM, Vedin V, Bohm S, Berghard A: Odorant-dependent, spatially restricted induction of c-fos in the olfactory epithelium of the mouse. J Neurochem 2005, 93:1594-1602.

3. Busto GU, Elie JE, Kermen F, Garcia S, Sacquet J, Jourdan F, Marcel D, Mandairon N, Didier A: Expression of Zif268 in the granule cell layer of the adult mouse olfactory bulb is modulated by experience. Eur $\mathrm{J}$ Neurosci 2009, 29:1431-1439.

4. Okuno H: Regulation and function of immediate-early genes in the brain: beyond neuronal activity markers. Neurosci Res 2011, 69:175-186.

5. Wisden W, Errington ML, Williams S: Differential expression of immediate early genes in the hippocampus and spinal cord. Neuron 1990, 4:603-614.

6. Worley PF, Bhat RV, Baraban JM, Erickson CA, McNaughton BL, Barnes CA: Thresholds for synaptic activation of transcription factors in hippocampus: correlation with long-term enhancement. J Neurosci 1993, 13:4776-4786.

7. Guzowski JF, Setlow B, Wagner EK, McGaugh JL: Experience-dependent gene expression in the rat hippocampus after spatial learning: a comparison of the immediate-early genes arc, cfos, and zif268. J Neurosci 2001, 21:5089-5098.

8. Lledo PM, Gheusi G, Vincent JD: Information processing in the mammalian olfactory system. Physiol Rev 2005, 85:281-317.

9. Mombaerts P: Axonal wiring in the mouse olfactory system. Annu Rev Cell Dev Biol 2006, 22:713-737.

10. Mori K, Takahashi YK, Igarashi KM, Yamaguchi M: Maps of odorant molecular features in the Mammalian olfactory bulb. Physiol Rev 2006, 86:409-433.

11. Gómez C, Briñón JG, Barbado MV, Weruaga E, Valero J, Alonso JR: Heterogeneous targeting of centrifugal inputs to the glomerular layer of the main olfactory bulb. J Chem Neuroanat 2005, 29:238-254

12. Kiselycznyk CL, Zhang S, Linster C: Role of centrifugal projections to the olfactory bulb in olfactory processing. Learn Mem 2006, 13:575-579.

13. Matsutani S, Yamamoto N: Centrifugal innervation of the mammalian olfactory bulb. Anat Sci Int 2008, 83:218-227.

14. Sallaz M, Jourdan F: Odour-induced c-fos expression in the rat olfactory bulb: involvement of centrifugal afferents. Brain Res 1996, 721:66-75

15. Kaupp UB: Olfactory signalling in vertebrates and insects: differences and commonalities. Nat Rev Neurosci 2010, 11:188-200.

16. Ronnett GV, Moon C: G proteins and olfactory signal transduction. Annu Rev Physiol 2002, 64:189-222.

17. Belluscio L, Gold GH, Nemes A, Axel R: Mice deficient in G(olf) are anosmic. Neuron 1998, 20:69-81.

18. Wong S, Trinh K, Hacker B, Chan GC, Lowe G, Gaggar A, Xia Z, Gold GH, Storm DR: Disruption of the type III adenylyl cyclase gene leads to peripheral and behavioral anosmia in transgenic mice. Neuron 2000, 27:487-497.

19. Brunet L, Gold GH, Ngai J: General anosmia caused by a targeted disruption of the mouse olfactory cyclic nucleotide-gated cation channel. Neuron 1996, 17:681-693.

20. Mandiyan VS, Coats JK, Shah NM: Deficits in sexual and aggressive behaviors in Cnga2 mutant mice. Nat Neurosci 2005, 8:1660-1662.

21. Lin W, Arellano J, Slotnick B, Restrepo D: Odors detected by mice deficient in cyclic nucleotide-gated channel subunit $\mathrm{A} 2$ stimulate the main olfactory system. J Neurosci 2004, 24:3703-3710.

22. Zhao H, Ivic L, Otaki JM, Hashimoto M, Mikoshiba K, Firestein S: Functional expression of a mammalian odorant receptor. Science 1998, 279:237-242.

23. Rubin BD, Katz LC: Optical imaging of odorant representations in the mammalian olfactory bulb. Neuron 1999, 23:499-511.

24. Mori $\mathrm{K}$, Sakano H: How is the olfactory map formed and interpreted in the mammalian brain? Annu Rev Neurosci 2011, 34:467-499.

25. Inaki K, Takahashi YK, Nagayama S, Mori K: Molecular-feature domains with posterodorsal-anteroventral polarity in the symmetrical sensory maps of the mouse olfactory bulb: mapping of odourant-induced Zif268 expression. Eur J Neurosci 2002, 15:1563-1574.

26. Matsumoto H, Kobayakawa K, Kobayakawa R, Tashiro T, Mori K, Sakano H, Mori $\mathrm{K}$ : Spatial arrangement of glomerular molecular-feature clusters in the odorant-receptor class domains of the mouse olfactory bulb. J Neurophysiol 2010, 103:3490-3500.
27. Uchida N, Takahashi YK, Tanifuji M, Mori K: Odor maps in the mammalian olfactory bulb: domain organization and odorant structural features. Nat Neurosci 2000, 3:1035-1043.

28. Guthrie KM, Anderson AJ, Leon M, Gall C: Odor-induced increases in c-fos mRNA expression reveal an anatomical "unit" for odor processing in olfactory bulb. Proc Natl Acad Sci USA 1993, 90:3329-3333.

29. Johnson BA, Farahbod H, Xu Z, Saber S, Leon M: Local and global chemotopic organization: general features of the glomerular representations of aliphatic odorants differing in carbon number. $J$ Comp Neurol 2004, 480:234-249.

30. Kobayakawa K, Kobayakawa R, Matsumoto H, Oka Y, Imai T, Ikawa M, Okabe M, Ikeda T, Itohara S, Kikusui T, Mori K, Sakano H: Innate versus learned odour processing in the mouse olfactory bulb. Nature 2007, 450:503-508.

31. Ben-Shaul Y, Katz LC, Mooney R, Dulac C: In vivo vomeronasal stimulation reveals sensory encoding of conspecific and allospecific cues by the mouse accessory olfactory bulb. Proc Natl Acad Sci USA 2010, 107:5172-5177.

32. Xu F, Schaefer M, Kida I, Schafer J, Liu N, Rothman DL, Hyder F, Restrepo D, Shepherd GM: Simultaneous activation of mouse main and accessory olfactory bulbs by odors or pheromones. I Comp Neurol 2005, 489:491-500.

33. Trinh K, Storm DR: Vomeronasal organ detects odorants in absence of signaling through main olfactory epithelium. Nat Neurosci 2003, 6:519-525.

34. Keller M, Baum MJ, Brock O, Brennan PA, Bakker J: The main and the accessory olfactory systems interact in the control of mate recognition and sexual behavior. Behav Brain Res 2009, 200:268-276.

35. de Castro F: Wiring olfaction: the cellular and molecular mechanisms that guide the development of synaptic connections from the nose to the cortex. Front Neurosci 2009, 3:52.

36. Stettler DD, Axel R: Representations of odor in the piriform cortex. Neuron 2009, 63:854-864.

37. Baker H, Cummings DM, Munger SD, Margolis JW, Franzen L, Reed RR, Margolis FL: Targeted deletion of a cyclic nucleotide-gated channel subunit (OCNC1): biochemical and morphological consequences in adult mice. J Neurosci 1999, 19:9313-9321.

38. Leinders-Zufall T, Cockerham RE, Michalakis S, Biel M, Garbers DL, Reed RR, Zufall F, Munger SD: Contribution of the receptor guanylyl cyclase GC-D to chemosensory function in the olfactory epithelium. Proc Natl Acad SCi USA 2007, 104:14507-14512.

39. Kippin TE, Cain SW, Pfaus JG: Estrous odors and sexually conditioned neutral odors activate separate neural pathways in the male rat. Neuroscience 2003, 117:971-997.

40. Dhungel S, Masaoka M, Rai D, Kondo Y, Sakuma Y: Both olfactory epithelial and vomeronasal inputs are essential for activation of the medial amygdala and preoptic neurons of male rats. Neuroscience 2011, 199:225-234.

41. Takahashi LK, Nakashima BR, Hong H, Watanabe K: The smell of danger: a behavioral and neural analysis of predator odor-induced fear. Neurosci Biobehav Rev 2005, 29:1157-1167.

42. Capone F, Venerosi A, Puopolo M, Alleva E, Cirulli F: Behavioral responses of 129/Sv, C57BL/6J and DBA/2J mice to a non-predator aversive olfactory stimulus. Acta Neurobiol Exp 2005, 65:29-38.

43. Lin Y, Bloodgood BL, Hauser JL, Lapan AD, Koon AC, Kim TK, Hu LS, Malik AN, Greenberg ME: Activity-dependent regulation of inhibitory synapse development by Npas4. Nature 2008, 455:1198-1204.

44. Yun J, Koike H, Ibi D, Toth E, Mizoguchi H, Nitta A, Yoneyama M, Ogita K, Yoneda Y, Nabeshima T, Nagai T, Yamada K: Chronic restraint stress impairs neurogenesis and hippocampus-dependent fear memory in mice: possible involvement of a brain-specific transcription factor Npas4. J Neurochem 2010, 114:1840-1851.

45. Ploski JE, Monsey MS, Nguyen T, DiLeone RJ, Schafe GE: The neuronal PAS domain protein 4 (Npas4) is required for new and reactivated fear memories. PLoS One 2011, 6:e23760.

46. Isogai Y, Si S, Pont-Lezica L, Tan T, Kapoor V, Murthy VN, Dulac C: Molecular organization of vomeronasal chemoreception. Nature 2011, 478:241-245.

47. Dhallan RS, Yau KW, Schrader KA, Reed RR: Primary structure and functional expression of a cyclic nucleotide- activated channel from olfactory neurons. Nature 1990, 347:184-187.

48. Waldeck C, Vocke K, Ungerer N, Frings S, Möhrlen F: Activation and desensitization of the olfactory CAMP-gated transduction channel: identification of functional modules. J Gen Physiol 2009, 134:397-408. 
49. Lin W, Margolskee R, Donnert G, Hell SW, Restrepo D: Olfactory neurons expressing transient receptor potential channel M5 (TRPM5) are involved in sensing semiochemicals. Proc Natl Acad Sci USA 2007, 104:2471-2476.

50. Sakano H: Neural map formation in the mouse olfactory system. Neuron 2010, 67:530-542.

51. Restrepo D, Arellano J, Oliva AM, Schaefer ML, Lin W: Emerging views on the distinct but related roles of the main and accessory olfactory systems in responsiveness to chemosensory signals in mice. Horm Behav 2004, 46:247-256.

52. Brand G: Olfactory/trigeminal interactions in nasal chemoreception. Neurosci Biobehav Rev 2006, 30:908-917.

53. Schaefer ML, Bottger B, Silver WL, Finger TE: Trigeminal collaterals in the nasal epithelium and olfactory bulb: a potential route for direct modulation of olfactory information by trigeminal stimuli. J Comp Neurol 2002, 444:221-226.

54. Kratskin I, Hummel T, Hastings L, Doty R: 3-Methylindole alters both olfactory and trigeminal nasal mucosal potentials in rats. Neuroreport 2000, 11:2195-2197.

55. Lecoq J, Tiret P, Charpak S: Peripheral adaptation codes for high odor concentration in glomeruli. J Neurosci 2009, 29:3067-3072.

56. Pírez N, Wachowiak M: In vivo modulation of sensory input to the olfactory bulb by tonic and activity-dependent presynaptic inhibition of receptor neurons. J Neurosci 2008, 28:6360-6371.

57. Serizawa S, Miyamichi K, Takeuchi H, Yamagishi Y, Suzuki M, Sakano H: A neuronal identity code for the odorant receptor-specific and activitydependent axon sorting. Cell 2006, 127:1057-1069.

58. Masahira N, Takebayashi H, Ono K, Watanabe K, Ding L, Furusho M, Ogawa Y, Nabeshima Y, Alvarez-Buylla A, Shimizu K, Ikenaka K: Olig2-positive progenitors in the embryonic spinal cord give rise not only to motoneurons and oligodendrocytes, but also to a subset of astrocytes and ependymal cells. Dev Biol 2006, 293:358-369.

59. Lehr HA, van der Loos CM, Teeling P, Gown AM: Complete chromogen separation and analysis in double immunohistochemical stains using Photoshop-based image analysis. J Histochem Cytochem 1999, 47:119-125.

60. Mofidi R, Walsh R, Ridgway PF, Crotty T, McDermott EW, Keaveny TV, Duffy MJ, Hill AD, O'Higgins N: Objective measurement of breast cancer oestrogen receptor status through digital image analysis. Eur J Surg Oncol 2003, 29:20-24.

doi:10.1186/1471-2202-13-140

Cite this article as: Bepari et al:: Visualization of odor-induced neuronal activity by immediate early gene expression. BMC Neuroscience 2012 $13: 140$

\section{Submit your next manuscript to BioMed Central and take full advantage of:}

- Convenient online submission

- Thorough peer review

- No space constraints or color figure charges

- Immediate publication on acceptance

- Inclusion in PubMed, CAS, Scopus and Google Scholar

- Research which is freely available for redistribution 